\title{
O Plano Nacional de Mineração 2030 e a Atividade Mineradora em Terras Indígenas
}

The 2030 National Mining Plan and the Mining Activity

in Indigenous Land

Karen Daniele de Araújo Pimentel ${ }^{1}$

Lucas Isaac Soares Mesquita ${ }^{2}$

Recebido em 28/01/2016 e aceito em 05/04/2016.

Resumo: O Ministério de Minas e Energia elaborou um Plano Nacional de Mineração, listando metas para quintuplicar a atividade mineradora no país e a elaboração do Novo Código da Mineração. O Plano trata a extração e transformação mineral como mera atividade a ser regulada em benefício das empresas, desconsiderando os impactos decorrentes, eflexibilizaa atividade em áreas de restrição legal. Como consequências ocorrem a destruição do meio ambiente e do modo de vida das comunidades que historicamente ocupam os territórios visados pela mineração, a exemplo dos povos indígenas. Questiona-se como o Estado Brasileiro observa os princípios democráticosno contexto neoliberal. Por fim, trataremos da questão da mineração em terras indígenas, a partir do art. 231 da CF e da Convenção 169 da OIT.

1 Graduanda em Direito pela Universidade Federal de Alagoas e membro do Núcleo de Estudos em Direito Internacional e Meio Ambiente (NEDIMA). Realiza pesquisa com ênfase em Direitos Humanos, Direito Ambiental e Urbanístico. E-mail: karendpimentel95@ gmail.com

2 Concluinte do curso de Direito pela Universidade Federal de Alagoas. Membro do Núcleo de Estudos em Direito Internacional e Meio Ambiente (NEDIMA) da FDA/UFAL. E-mail: lucasismesquita@gmail.com 
Palavras-chave: mineração; plano; impactos socioambientais; indígenas. Abstract: The Ministry of Mines and Energy elaborated a National Plan of the Mining, which lists goals to increase five times the mining activity in the country and the elaboration of the New Code of Mining. The Plan treats the mineral extraction and processing as a mere activity to be regulated for the companies benefit, disregarding the impacts and easing the mining activity in areas with legal restriction. As consequences occurs the destruction of the environment and the way of life of the communities that occupies the territories targeted by the mining, for instance, the indigenous people. We question how the Brazilian Estate observes its democratic principles in the neoliberal context. At least, we will treat the question of the mining in indigenous lands, using the article 231 of the Federal Constitution and the OIT 169 Convention.

Keywords: mining; plan; impacts; indigenous.

\section{INTRODUÇÃO}

Em 2010, o Ministério de Minas e Energia, por meio da Secretaria de Geologia, Mineração e Transformação Mineral, publicou o Plano Nacional de Mineração 2030 (PNM - 2030), cujo objetivo é "nortear as políticas de médio e longo prazos que possam contribuir para que o setor mineral seja um alicerce para o desenvolvimento sustentável do País nos próximos 20 anos" (BRASIL, 2010: XIII). Tal documento, erguido a partir dos alicerces da "i) governança pública eficaz, ii) agregação de valor e adensamento do conhecimento por todas as etapas do setor mineral, e iii) sustentabilidade" (Idem, Ibidem: 6) tem como uma de suas principais metas, resultado desse novo planejamento estratégico, a elaboração de um novo Código de Mineração.

A principal problemática do PNM - 2030 é a insuficiência, ou completa ausência, de uma visão crítica aos danos de ordem econômica, ambiental ou social causadas pela mineração. Parte-se do pressuposto que a mineração é sempre benéfica, cabendo, portanto uma mera regulamentação técnica, com um planejamento de metas a triplicar 
(ou quintuplicar, em alguns casos) a atividade mineradora no território brasileiro num intervalo de duas décadas.

Apesar de parecer distante da nossa realidade ou demasiada técnica, a questão da mineração, da elaboração e consequente aprovação do novo marco legal estão na ordem do dia. Parte do que consumimos é resultado da cadeia produtiva que se inicia com a extração do minério em sua forma bruta. Os atingidos pela mineração, que vivem nas ou próximas às áreas de extração sentem de forma direta as consequências da atividade mineradora, seja no inchamento de suas cidades, na escassez de água, aumento da violência, contaminação do solo e do ar, perda de território, entre outros. Triplicar a mineração no país não é simplesmente aumentar os lucros advindos da venda de commodities minerais. É aumentar também os impactos sobre o meio ambiente, as populações e colocar em questão se o "desenvolvimento" de uma nação mede-se somente com o crescimento do Produto Interno Bruto.

Uma questão preocupante é a necessidade apontada pelo MME do estabelecimento de diretrizes para a mineração em áreas com restrição legal, entre elas terras indígenas e quilombolas, áreas para a reforma agrária, sítios arqueológicos e fossíferos e reservas ambientais. Apesar da utilização de um termo imparcial - "regulamentação" - a leitura atenta do tópico do PNM que se debruça sobre a questão, nos faz perceber que o que se discute, na verdade, é a flexibilização dessas restrições em nome do desenvolvimento minerário. Na concepção dos elaboradores do projeto (governo brasileiro!), antes de bloquear tais áreas, deveria haver um conhecimento geológico do solo e subsolo da região, sob pena de prejuízo dos interesses nacionais, regionais ou locais (BRASIL, 2010: 126).

Discute-se, portanto, a partir do "interesse nacional" meramente as questões lucrativas, transpondo-as sobre todas as outras que erguem o Estado Democrático de Direito Brasileiro, entre elas a justiça social e o direito à cultura dos povos indígenas e quilombolas. Este debate, no entanto, está longe de ser encerrado e demonstra a correlação de forças que está por trás da questão, isto é, a disputa de um modelo de desenvolvimento para o nosso país e a necessidade de assegurarmos nossa soberania econômica.Desta forma, o artigo buscará, por meio 
de um estudo teórico do tema ao qual se propõe, a análise de obras relacionadas à mineração no Brasil, mais especificamente sobre mineração em terras indígenas, tendo como ponto de partida o Plano Nacional de Mineração, o artigo 231 da Constituição Federal e outras legislações ordinárias.

No primeiro capítulo, apresentaremos um breve contexto acerca da atividade mineradora na América Latina, apontando as principais modificações operadas a partir do neoliberalismo e as principais diferenças pós ascensão dos governos de "esquerda" na região. Pretende-se ainda questionar a intencionalidade da produção normativa, com mera função de regulamentar o setor minerário, em contraste com os ideais da soberania econômica e do desenvolvimento nacional.

Já no segundo capítulo, traremos algumas das principais consequências sociais, ambientais e econômicas ignoradas ao longo do Plano Nacional de Mineração. Essas consequências perpassam a questão ambiental da degradação do meio físico dos territórios, elas se manifestam também na mudança radical do modo de vida das comunidades atingidas pela atividade minerária. Destacam-se nesse aspecto os inúmeros conflitos territoriais que vêm explodindo nas regiões mais visadas pela indústria da mineração.

O terceiro capítulo trata especificamente da questão da mineração em terras indígenas, identificando as principais tentativas de legislação no tocante ao tema, a (in)observância da Convenção 169 da OIT e a consequente repercussão no modelo de cidadania pelo qual se molda o Estado Brasileiro.

\section{DISCUTINDO O DESENVOLVIMENTO: QUEM GANHA COM ESSE PLANO?}

Ainda que no campo das ciências sociais aplicadas, tendemos a pensar o Direito como algo a parte da realidade. Quando não, como este configura status jurídico a determinada relação ou fato social através da incidência da norma e uma relação de autoridade. O que passará a se discutir nas páginas a seguir, no entanto, não é tal raciocínio 
a que somos levados a trilhar em nossa formação jurídica, mas debateremos a "imparcialidade" e extrema relação da norma jurídica (entendida em sua perspectiva mais ampla), com os sistemas econômico e político, bem como a importância de se questionar a elaboração das leis analisadas em benefício das empresas mineradoras, pondo em xeque os próprios princípios defendidos pela Constituição Federal, tida como carta máxima do ordenamento jurídico brasileiro.

$\mathrm{Na}$ visão de Milton Santos o abismo existente na sociedade e na economia determina a amplitude do conflito, e a existência destes conflitos importa a produção de normas, isto é, a regulação daqueles (SANTOS, 2006: 228). Com isso, temos a proliferação de regulações - que algumas vezes são opostas, portanto, conflituosas. O mercado não consegue dar respostas a tal conflito. Resultado: uma questão que aparentemente seria de ordem privada, a exemplo da regulação da extração de minérios no solo brasileiro, de interesse das empresas, torna-se de ordem pública, de interesse público, por não só dizer respeito acerca da extração e produção daquele mineral, mas por repercutir em uma rede de relações sociais e jurídicas que vão além das atividades das empresas (Idem, Ibidem: 228). Ainda para o mencionado autor:

A corporatização do território, com a destinação prioritária de recursos para atender às necessidades geográficas das grandes empresas, acaba por afetar toda a sociedade, já que desse modo a despesa pública ganha um perfil largamente desfavorável à solução de problemas sociais e locais (SANTOS, 2006: 229).

Apesar de sermos a sétima economia mundial, e tal fato ser medido como um fator de desenvolvimento perante os outros países, o PNM - 2030 é mais um indício do fortalecimento do perfil primário exportador brasileiro no contexto de reinserção na Divisão Internacional do Trabalho, que nos coloca enquanto um país de economia dependente, a nível econômico, da conjuntura internacional.

O Brasil teria iniciado, assim, um processo de desindustrialização, que não configuraria, como nos países centrais, uma trans- 
ferência de mão-de-obra do setor industrial para outros setores mais avançados tecnologicamente ou de serviços, mas seria um processo regressivo, que transfere mão-de-obra para os setores agrícolas, mineradores, agroindustriais e para as chamadas indústrias "maquiladoras", com baixo valor agregado, ampliando o desemprego e o baixo dinamismo econômico (BERCOVICI, 2011: 353).

Importante salientar que tal reversão reprimarizante não é um fenômeno característico somente do Brasil, mas da América Latina como um todo, principalmente após golpes militares e adesão ao Consenso de Washington.

Para além do papel de submissão aos países desenvolvidos, a América Latina possui uma "reserva fundamental de recursos estratégicos como [...] a água, energia de origem fóssil (petróleo), minerais e biodiversidade em geral" (SCOTTO, 2011: 3-4). São diversos os fatores que apontam o "boom" da extração minerária na região, entre eles: (a) a emergência da economia asiática e a necessidade de matéria prima e (b) a descoberta, entre 1990 e 2000, de abundantes reservas de minerais, principalmente no Brasil, Chile e Peru (Idem, Ibidem: 4).

Gabriela Scotto aponta o capitalismo neoliberal pós-ditaduras, na década de 1990, como principal conjuntura de mudanças pró-empresas, já que foi nessa época em que boa parte dos países definiu modificações nas legislações mineiras (Idem, Ibidem: 10). Fato é que, tanto sob a bandeira de empresas transnacionais, quanto estatais com o comportamento de empresas transnacionais ${ }^{3}$, a legislação e a política destes países vêm sendo flexibilizadaS para favorecimento de tais corporações em detrimento dos demais impactos que serão apontados ao longo do trabalho. Tal flexibilização coloca também à disposição destas empresas diversos direitos referentes à construção da cidadania brasileira e latino-americana.

3 São as empresas que possuem caráter público apenas no nome, já que suas estratégias e lucros são baseados "na competitividade, redução de custos, aumento da rentabilidade e persistência dos impactos sociais e ambientais". (GUDYNAS, 2009b) 
Para Eduardo Gudynas, há de se diferenciar a recente extração de minérios na América do Sul em dois momentos distintos: o extrativismo convencional, que perdurou nas décadas de 1980 e 1990, e o neo-extrativismo, típico dos anos 2000 e 2010. Na primeira fase, o papel do Estado é limitado, caracterizado pelo auge do período neoliberal, de liberação do fluxo de capital e no qual a intervenção estatal vinha no sentido de flexibilizar ou reduzir a legislação laboral, ambiental e territorial. Abrem-se as fronteiras para a atuação de diversas empresas transnacionais. (GUDYNAS, 2009a: 194-195) Já para o neo-extrativismo, um fator diferencial e vitorioso para a sua consolidação é a presença de governos de "esquerda" nos países da América Latina, que aumentam a presença do Estado, mas no sentido de institucionalizar as práticas neoliberais, justificando-se como progressistas através de programas sociais e o consequente apassivamento dos movimentos sociais. Neste último modelo, em nome do desenvolvimento, o Estado é muito ágil no que diz respeito ao atendimento das necessidades das empresas mineradoras e petrolíferas, mas é limitado no que tange à defesa e efetivação dos direitos da cidadania. (Idem, 2009b) Assim sendo, o autor é categórico ao afirmar que "el neo-extractivismo es funcional a la globalización comercial - financieira y mantiene la inserción internacional subordinada de América del Sur"(Idem, 2009a: 198).

Exportar minérios não torna (nem tornará) o Brasil, ou qualquer outro país da América Latina, desenvolvido. O crescimento estratosférico da mineração nos últimos anos não deve ser analisado apenas por seus ganhos. É limitado, primeiro porque os recursos naturais a serem explorados são finitos e segundo porque também há uma grande volatilidade no mercado de minérios. Os superlucros da mineração, além de mal distribuídos, são passageiros. O que pretende o governo brasileiro ao entregar seus recursos naturais a baixo custo, comprometendo a própria "soberania econômica" (artigo 170, I, CF)? E mais: com as consequências e impactos apresentados, não há qualquer ressalva por parte do governo brasileiro na aplicação do plano?

A ordem global, representada pelas empresas globais e transnacionais, impõe a todos os países subdesenvolvidos uma mesma racionalidade (SANTOS, 2006: 230) - que não vem a ser a defesa dos direitos 
humanos, da natureza ou de qualquer outro princípio erigido em qualquer carta constitucional dos países em contento -, mas sim as suas normas particulares, indiferentes às localidades em que se inserem. (Idem, Ibidem: 228) Cumprindo a cartilha do Banco Mundial, do Fundo Monetário Internacional, que correspondem à burguesia internacional, bem como a setores da burguesia nacional ${ }^{4}$, o governo brasileiro faz uma opção de modelo de desenvolvimento que beneficia tais setores em detrimento do benefício das classes que mais precisam.

Há, no caso em estudo, um direto descumprimento ao que preceitua a nossa constituição, que inclui no artigo $3^{\circ}$, uma norma-fim ${ }^{5}$, princípios de política social e econômica a serem cumpridos pelo Estado Democrático de Direito brasileiro. Entre essas questões, Gilberto Bercovici enfatiza a "supremacia do povo como sujeito da soberania, rechaçando a manutenção dos interesses privados de uma classe ou grupo dirigente" (BERCOVICI, 2011: 208-209). A Constituição, por seu viés econômico, teria por funções a "ordenação da atividade econômica, a satisfação das necessidades sociais e a direção do processo econômico geral" (Idem, Ibidem: 210). Importante ressaltar que a garantia do desenvolvimento nacional aparece no artigo $3^{\circ}$, II, da Constituição Federal como um dos objetivos da República (Idem, Ibidem: 218).

Da soberania econômica decorre a ideia de controle nacional de recursos naturais e estratégicos, nomeadamente os minérios e o petróleo. (Idem, Ibidem: 224) Assim, as demandas internas do país suscitaram a elaboração de legislações que visavam a regulamentação e defesa do povo brasileiro em determinados contextos, a saber: a ativi-

4 O Comitê Nacional dos Territórios Frente à Mineração entrou com pedido de Quebra de Decoro Parlamentar contra o Deputado Federal Leandro Quintão (PMDB - MG), relator da Comissão do projeto de Código de Mineração na Câmara dos Deputados, que em 2010 teve cerca de $20 \%$ de sua campanha eleitoral financiada por empresas do setor da mineração. Tal pedido foi negado pelo Presidente da Câmara dos Deputados, Henrique Alves (PMDB - RN), sob justificativa de que o projeto não estaria direcionado a nenhuma empresa específica, tratando de "regras gerais, aplicáveis indistintamente a todas as empresas que atuam no setor". Na campanha eleitoral de 2014, Leonardo Quintão teve $37 \%$ de sua campanha financiada por empresas da mineração. (SOUZA, 2014).

5 As normas fins são entendidas como aquelas que dispõem de um objetivo a ser perseguido e cumprido pelo Estado. 
dade garimpeira, a mineração em terras indígenas, o regime de concessão, as relações entre mineração e meio ambiente, entre outras.

No entanto, a adesão ao neoliberalismo por meio do "Consenso de Washington" e a substituição por um Estado Enxuto, tecnocrático, de menor influência na economia, fez com que boa parte das legislações complementares previstas na Constituição, a exemplo do art. 231 que trata da mineração em terras indígenas, não fossem elaboradas (Idem, Ibidem: 246). É a partir desse momento em que o Estado aparenta "ter renunciado a sua soberania em matéria econômica" (Idem, Ibidem: 241).

Temos um Estado submisso às necessidades do mercado, que comanda sua produção normativa, bem como a violação de direitos já "conquistados", colocando na ordem do dia outras questões que não as levantadas historicamente pelos movimentos sociais.

\begin{abstract}
Este fenômeno [blindagem da constituição financeira] ocorre em um contexto de estado de exceção econômico permanente, em que se utilizam as medidas emergenciais a todo momento para salvar os mercados, caracterizando uma subordinação do Estado ao mercado, com a exigência constante de adaptação do direito interno às necessidades do capital financeiro, que busca reduzir a deliberação democrática ao mínimo necessário, como se esta fosse uma mera formalidade. (Idem, Ibidem: 242)
\end{abstract}

Deste panorama de correlação de forças fica mais "fácil" compreender o que está acontecendo no campo da mineração brasileira e por quais motivos nossas análises não são as mais otimistas possíveis.

\title{
2. QUEM PAGA O PREÇO DA MINERAÇÃO?
}

"São irreversíveis, isso é muito importante. Não é uma coisa que pode ter um impacto que a gente diz: OK, depois a gente recupera e fica tudo como era antes". (ENQUANTO, 2013) É essa a fala que dá início ao documentário "Enquanto o trem não passa" e reflete a gravidade dos impactos causados pela atividade mineradora. $\mathrm{O}$ documentário mostra de forma sucinta e precisa os prejuízos socioam- 
bientais causados pela mineração em solo brasileiro e os perigos do seu avanço desenfreado.

Crescendo $550 \%$ apenas no último decênio, a produção mineral partiu de US\$ 7,7 bilhões chegando a US\$ 50 bilhões (IBRAM, 2012: 7). Segundo o último levantamento feito pelo Departamento Nacional de Produção Mineral (DNPM) em 2011, são 8.870 mineradoras atuando no Brasil, a maior concentração está na região Sudeste, com 3.609 empresas (Idem, Ibidem: 4). O país ainda figura entre as primeiras posições mundiais na produção de minerais, sendo o primeiro lugar na produção de Nióbio (Idem, Ibidem: 7). Essa produção em escala e expansão demanda muita mão de obra, sendo 175 mil trabalhadores formalmente registrados no setor em 2011 e cerca de 500 mil, levando em consideração o alto nível de informalidade ainda presente na atividade mineradora (Idem, Ibidem: 10). E o crescimento do setor não para por aí, visto que a previsão de investimentos na área da mineração chega a US\$ 75 bilhões de 2012 a 2016 (ARAÚJO et al, 2014: 15).

Frederico Martins, analista ambiental do ICMBio, em entrevista concedida ao documentário "Minerando Conflitos", explica o que é a mineração: "Mineração é: desmatamento, 'né’: supressão da vegetação; rebaixamento do lençol; explosão 'pra' detonar e quebrar a rocha; e lavra” (MINERANDO, 2014). Segundo o especialista, não há outra fórmula, a extração mineradora acontece sempre da mesma forma, ou seja, é uma atividade essencial e necessariamente nociva ao meio ambiente. Sem desmatar e destruir, o homem não consegue atuar na natureza de forma a extrair seus recursos minerais.

As consequências dessa intensa produção mineradora podem ser constatadas no meio ambiente e - principalmente -, nas vidas daqueles que trabalham no garimpo e vivem nas regiões mais afetadas pela atividade. A mineração, além de alterar o solo provocando erosão e alteração da paisagem, ainda é causa de intenso desmatamento e comprometimento da fauna e flora da região. Outro problema central é a dispersão de metais pesados, que contaminam a água e compromete a saúde das comunidades vizinhas aos locais de garimpo. Ademais, quando esses impactos não são remediados imediatamente, o que acontece é uma proliferação dos chamados "passivos ambientais", 
que são as minas abandonadas depois da extração, que continuam mesmo após décadas sem uso - a contaminar o ambiente e afetar o modo de vida da população (ARAúJO et al, 2014: 16).

Se os efeitos da mineração degradam de forma irreversível o meio ambiente, o mesmo acontece na vida das comunidades. Não é só a alteração física do ambiente que afeta o cotidiano da população local, mas também a lógica predatória da indústria mineradora. Isso acontece porque as empresas se instalam na região, mudam toda a dinâmica e paisagem local, exploram os recursos até que se esgotem e nada é revertido às pessoas que foram afetadas. As mineradoras vão em busca de novos campos de extração deixando seu rastro de destruição por onde passam: contaminação das águas, desmatamento, poluição, além do total desmantelamento da organização socioeconômica local. Explica Frederico Martins:

A matriz econômica dessa região aqui, ela não evolui com recur-
so da mineração. Ele é simplesmente tirado, vendido de forma
bruta: sem beneficiamento, sem verticalização, sem agregar va-
lor nenhum. E a matriz econômica aqui não altera, então essa
região não 'tá' preparada 'pro' fim da mineração. Quando acabar
a mineração aqui, isso aqui vai virar um bolsão de miséria (MI-
NERANDO, 2014).

Rose Lima, Agente da Comissão Pastoral da Terra, explica que há um problema concreto: uma ferrovia que passa por grandes comunidades com uma população com demandas socioeconômicas extremamente grandes e que, de fato, historicamente, nunca foram beneficiadas por um centavo desse minério que elas veem passar todo dia em frente às suas portas. Enquanto o esgoto escorre na frente das casas, enquanto há o barulho permanente daquele trem que passa nas suas portas, impedindo que você tenha um fluxo e que tenha de esperar horas para transitar. Além disso, explica Rose: as populações vivem sem nenhum acesso a políticas públicas e onde tem são extremamente incompletas enquanto você vê milhares e milhares de toneladas de ferro sendo exportadas diariamente nas suas portas e você não vê isso na sua vida concreta enquanto desenvolvimento (Idem, Ibidem). 
Todos esses fatores constituem uma bomba-relógio prestes a explodir a qualquer momento, e que já explodiu em várias regiões, disseminando diversos conflitos sociais. O Observatório de Conflitos Mineiros da América Latina (OCMAL) realizou um mapa desses conflitos. Segundo a base de dados desenvolvida pelo observatório, são 205 conflitos registrados, sendo 215 projetos de mineradoras envolvidos nos conflitos (OCMAL, ?). Especificamente no Brasil, o Relatório Conflitos no Campo da Comissão Pastoral da Terra aponta que: "dos 816 conflitos de terra registrados em 2012, 36 envolvem a indústria de mineração, afetando 3.705 famílias" (FAUSTINO e FURTADO, 2013: 39).

Como forma de demonstrar o processo agressivo de expansão da indústria mineradora, tomamos como exemplo a Estrada de Ferro Carajás (EFC). Esta passa por 27 municípios, 28 Unidades de Conservação, além de atravessar diretamente mais de 100 comunidades quilombolas e indígenas no Pará e no Maranhão (FAUSTINO e FURTADO, 2013: 19). Apenas ao longo da EFC, são mais de cem comunidades quilombolas e indígenas afetada pela mineração. Essa população, além de ter sua principal fonte de subsistência e renda contaminada e destruída, quando não lhes é extirpada - a terra, visto que a grande maioria vive da agricultura familiar - ainda tem o seu modo de vida completamente transformado. O problema é ainda mais grave quando percebemos que essas comunidades têm como principal patrimônio histórico-cultural seu modo singular de vida. Os povos indígenas e quilombolas, historicamente perseguidos desde a colonização do Brasil, sofrem mais uma vez com o avanço do capitalismo em expansão. Se em outra época foram os latifúndios voltados à cana-de-açúcar os que tomaram seus territórios, o ferro é o açúcar do século XXI.

\section{MINERAÇÃO EM TERRAS INDÍGENAS}

No capítulo dedicado aos "Desafios para a Geologia, Mineração e Transformação Mineral”, o PNM - 2030 dedica um subtópico à Mineração em Áreas com Restrição Legal. O Plano traz, como exemplificação dessas regiões, "novas áreas de preservação ambiental, demarcação de terras indígenas e de quilombolas, exigências de reservas legais no 
caso de propriedades rurais, [...] áreas para a Reforma Agrária e [...] áreas de fronteiras" (BRASIL, 2010: 54).

A principal ideia colocada pelo PNM é a de que o crescimento da demanda de minérios acarretará maior pressão para aumento da produção mineral, que encontrará nestas áreas de restrição legal um entrave a sua expansão. (Idem, Ibidem: 54 ) Intenciona-se uma harmonização entre os interesses do setor minerário com as outras partes envolvidas, considerando o desenvolvimento sustentável enquanto eixo central de tal harmonia. (Idem, Ibidem: 54)

Entre as ações propostas, está o "apoio à aprovação de lei que regulamente o aproveitamento dos bens minerais nas terras indígenas, segundo dispõe o Artigo 231 da Constituição Federal de 1988" (Idem, Ibidem: 57). O artigo supramencionado assim dispõe:

Art. 231. São reconhecidos aos índios sua organização social, costumes, línguas, crenças e tradições, e os direitos originários sobre as terras que tradicionalmente ocupam, competindo à União demarcá-las, proteger e fazer respeitar todos os seus bens.

$[\ldots]$

$\S 3^{\circ}$ - O aproveitamento dos recursos hídricos, incluídos os potenciais energéticos, a pesquisa e a lavra das riquezas minerais em terras indígenas só podem ser efetivados com autorização do Congresso Nacional, ouvidas as comunidades afetadas, ficando-Ihes assegurada participação nos resultados da lavra, na forma da lei.

$\S 4^{\circ}$ - As terras de que trata este artigo são inalienáveis e indisponíveis, e os direitos sobre elas, imprescritíveis.

$\S 5^{\circ}$ - É vedada a remoção dos grupos indígenas de suas terras, salvo, "ad referendum" do Congresso Nacional, em caso de catástrofe ou epidemia que ponha em risco sua população, ou no interesse da soberania do País, após deliberação do Congresso Nacional, garantido, em qualquer hipótese, o retorno imediato logo que cesse o risco. 
$\S 6^{\circ}$ - São nulos e extintos, não produzindo efeitos jurídicos, os atos que tenham por objeto a ocupação, o domínio e a posse das terras a que se refere este artigo, ou a exploração das riquezas naturais do solo, dos rios e dos lagos nelas existentes, ressalvado relevante interesse público da União, segundo o que dispuser lei complementar, não gerando a nulidade e a extinção direito a indenização ou a ações contra a União, salvo, na forma da lei, quanto às benfeitorias derivadas da ocupação de boa fé.

[...] (BRASIL, 1988).

A Constituição Federal dedicou-se a pensar a questão da demarcação de terras indígenas no sentido de proteger a identidade indigenista, não só pelo direito à moradia daqueles. Isto quer dizer que o direito à terra indígena não se resume a garantia de uma parte de terreno em qualquer lugar do país, mas sim do direito à identidade coletiva, cujo desrespeito pode trazer "danos irreparáveis para a sua proteção física e cultural” (BERCOVICI, 2011: 231-232). Não houve, desde 1988, adaptação total da legislação indigenista aos parâmetros da Constituição Federal. Segundo Gilberto Bercovici, o "Estatuto do Índio", Lei n 6.001, de 19 de dezembro de 1973, não tem aplicação nos casos de mineração em terras indígenas, "pois esta lei desconsidera a concepção adotada pela Constituição de usufruto exclusivo indígena, com as exceções dos artigos $176, \S 1^{\circ}$ e $231, \S 3^{\circ}$ e $6^{\circ}$ [...]" (Idem, Ibidem: 233). Tais exceções exigem a observância do relevante interesse público da União e o cumprimento dos requisitos constitucionais, que, resumidamente, seriam: "1. Lei que estabeleça as condições específicas de como pode se dar a exploração ou aproveitamento; 2. Autorização do Congresso Nacional; 3. Ouvir as comunidades indígenas" (MAIOR, s/d).

Apesar de ser um tema antigo, o debate sobre a mineração em terras indígenas foi retomado após a descoberta de diamantes na Terra Indígena de Roosevelt, do povo indígena Cinta Larga, no fim da década de 1990. As principais tentativas de regulamentação dessa atividade foram: (a) PL 1.610/96; (b) PL 2.057/91; (c) Projetos apresentados pelo Governo; (d) Projeto Substitutivo ao PL 1.610/91. (CURI, 2007: 225) 
O Projeto de Lei 1.610/96, de autoria do senador Romero Jucá (PFL - RR), já foi aprovado uma vez pelo Senado Federal, atualmente tramitando na Câmara dos Deputados em Comissão Especial. Além de ser um PL que trata exclusivamente acerca da exploração mineral em terras indígenas, o projeto é criticado pelos movimentos sociais (principalmente indígenas) e parlamentares que defendem os interesses indígenas por conter "proposições inconstitucionais e lesivas aos direitos dos índios" (Idem, Ibidem: 227). Entre 2006 e 2007 o Governo Federal apresentou algumas propostas referentes ao assunto que, mais tarde, culminaram numa tentativa de atualização do PL 1.610. No entanto, esse conjunto de medidas não foi bem acolhido pelos povos indígenas. Contrários aos desmembramentos dos seus direitos e defensores de que o assunto deveria ser tratado no Estatuto dos Povos Indígenas (PL 2.057/91, que se encontra paralisado desde 1994) (CURI, 2007: 227).

Desde 2003 o Brasil se comprometeu a aplicar a Convenção 169 da OIT, com a aprovação do Decreto Legislativo n. 143 de 2002. Dessa maneira, os povos indígenas têm o direito de "participar da formulação, implementação e avaliação de planos e programas de desenvolvimento nacional e regional que possam afetá-los diretamente" (OIT, 1989), como é o caso do PNM. Além disso, a Convenção ainda traz que os governos signatários terão a responsabilidade de desenvolver ações integradas com os povos para garantir seus direitos, criando meios de consulta pelos quais estes possam participar livremente, tomando medidas em cooperação para proteger e preservar o meio ambiente nos territórios por eles habitados, entre outros compromissos (Idem, Ibidem).

No entanto, não basta apenas que a consulta aconteça, mas esta deve ser efetiva, ou seja: a participação dos povos indígenas deve ter interferido de fato nos resultados da Comissão Especial destinada ao projeto. Os principais afetados pelo texto legislativo em questão têm o direito de ver refletidos os seus interesses e exercer a influência direta nos planos que podem mudar o rumo e suas vidas. O processo de consulta prévia é tão importante que é possível defini-lo como: 
um direito de influência efetiva sobre as decisões do Estado, por meio do qual se faz obrigatória a inclusão dos resultados das discussões levantadas nas reuniões com os diretamente afetados no conteúdo e na motivação destas decisões, que por sua vez não podem ser arbitrárias nem autoritárias. (INSTITUTO SOCIOAMBIENTAL, s/d).

Apesar da importância da consulta prévia, direito reconhecido pelo Brasil internacionalmente ao ratificar a Convenção 169 da OIT, o cenário político brasileiro aponta para um retrocesso na efetivação desse direito. Isso porque ainda é forte a ligação entre deputados e empresas de mineração, o forte lobby exercido por essas corporações faz o país recuar no respeito aos interesses dos povos indígenas. A situação é tão grave que é reconhecida pelo próprio presidente da Comissão Especial criada para a analisar o PL 1.610, em entrevista ao site O Eco: "A maioria dos deputados da Comissão está comprometida com o setor da mineração. Dos mais de 20 deputados na Comissão Especial, apenas 4 ou 5 efetivamente trabalham para que a máxima participação dos índios seja contemplada" (KOKUBO, 2013).

Enquanto o imbróglio político não se resolve, o garimpo continua a invadir os territórios indígenas deixando o cenário de devastação provocado pela atividade. Para além de reconhecer os direitos dos povos indígenas, a mudança da situação brasileira quanto ao avanço da mineração perpassa também a transformação do paradigma atual de desenvolvimento. O projeto de nação "neodesenvolvida" pensado para o Brasil não incluiu (e não por falta de aviso ou puro deslize) os índios, os quilombolas e demais comunidades vulneráveis. O crescimento desenfreado do capitalismo nos países em desenvolvimento não se preocupa em destruir o que encontre pela frente, sejam florestas, rios ou comunidades inteiras.

\section{CONCLUSÃO}

No panorama traçado ao longo do trabalho, percebe-se que o Estado Brasileiro toma partido a favor das empresas em detrimento da participação cidadã e da observância dos princípios constitucionais mais 
básicos. Não se mede o desenvolvimento pelo crescimento econômico, sob risco de, pelo contrário, perpetuar-se o subdesenvolvimento (BERCOVICI, 2011: 358). São necessárias mudanças estruturais, uma "política deliberada de desenvolvimento [...], um projeto político mobilizador" (Idem, Ibidem: 358). Aumentar a produção de "commodities" minerárias no Brasil e estimular o consumo de massas, apesar de surtir efeito no PIB, pouco contribuirá para nosso desenvolvimento, já que tal riqueza não será distribuída. E mais: tal riqueza é conquistada a partir de violações aos preceitos de cidadania e sociabilidade, a exemplo da mineração ilegal, da expulsão de pessoas de suas casas, perseguições a grupos indígenas e quilombolas, derrubada de matas nativas, entre outros. A receita de desenvolvimento adotada pelo governo brasileiro é destrutiva às riquezas minerais do país, ao seu povo e à democracia brasileira.

Apesar de parecer uma observação óbvia, os minérios são recursos minerais "não renováveis", logo, a intensificação da sua retirada deve ser tomada com todas as precauções. O projeto de desenvolvimento brasileiro deve incluir a harmonização entre planejamento econômico e ecológico, do contrário, o futuro estará cada vez mais ameaçado. É preciso pensar, para além da defesa das reservas naturais, numa ideia de justiça socioambiental, alternativa ao produtivismo mineral e agropecuário. Neste mesmo diapasão, fortalecer os direitos coletivos e territoriais, que incluem o respeito e proteção aos povos indígenas e tradicionais.

Além da necessidade de maior autonomia perante o neoliberalismo/globalização, urge, para contribuirmos com a nossa real soberania econômica a abertura de debates públicos acerca dos rumos do país. As pessoas atingidas precisam ser ouvidas, o povo, enquanto agente político, deve ser levado em consideração. Não apenas ouvido, o povo deve influenciar diretamente nas decisões, a participação das pessoas atingidas deve ser efetiva. Dessa forma é possível construir um caminho democrático para que a exploração de nossos recursos minerais estratégicosatenda os anseios internos e não os do mercado, essencialmente insaciável.

Para Bercovici, em uma democracia verdadeira, soberania econômica e popular são sinônimos e "não significam apenas que o poder 
emana do povo, mas também que este povo tem direito à terra, [...] aos frutos do seu trabalho e [...] ao excedente produzido pela exploração de seus recursos naturais, que são públicos [...]" (BERCOVICl, 2011: 360). Seguindo essa premissa, não resta dúvida sobre a necessidade pulsante de criar e fortalecer os meios já existentes de participação popular nas decisões institucionais. Dentro dessa necessidade, destaca-se como primordial nas questões referentes à mineração a consulta prévia efetiva aos povos indígenas que terão seus territórios afetados.

A participação popular, entretanto, não deve se restringir às decisões políticas. Invertendo a lógica privatista neoliberal, é preciso que o povo também participe da divisão dos lucros obtidos pela atividade. A riqueza gerada deve ser revertida em benefícios para as comunidades atingidas e para a população brasileira como um todo, a verdadeira dona de todos os recursos extraídos em solo nacional. A questão pode ser resumida em uma fala simples:

A solução para os problemas causados pelo modelo de exploração mineral e os recursos naturais da Amazônia, a solução não vai sair dos governos, não vai sair dos deputados, senadores, de vereadores. Essa solução vai sair da sociedade. Vai sair do povo brasileiro compreendendo que a riqueza que existe no solo e no subsolo pertence a cada um de nós brasileiros (MINERANDO, 2014).

\section{REFERÊNCIAS}

ARAÚJO, Eliane Rocha et al. Recursos minerais e comunidade: impactos humanos, socioambientais e econômicos. Rio de Janeiro: CETEM/MCTI, 2014.

BERCOVICI, Gilberto. Direito Econômico do Petróleo e dos Recursos Minerais. São Paulo: QuartierLatin, 2011.

BRASIL. Constituição da República Federativa do Brasil de 1988. Brasília: Senado Federal, 1988. 
BRASIL. Plano Nacional de Mineração 2030: Geologia, Mineração e Transformação Mineral. Brasília: Ministério de Minas e Energia, 2010.

CURI, Melissa Volpato. Aspectos Legais da Mineração em Terras Indígenas. Revista de Estudos e Pesquisas, v. 4, n. 2. Brasília: FUNAI, dez. 2007, pp. 221-252. Disponível em: <<http://www.funai.gov.br/arquivos/conteudo/cogedi/pdf/Revista-Estudos-e-Pesquisas/revista_estudos_pesquisas_v4_n2/Artigo_6_Melissa_Volpato_Aspectos_legais_ da_mineracao.pdf $\gg$. Acesso em: 15 jan. 2015.

ENQUANTO o trem não passa. Mídia NINJA, 2013. Disponível em: <https://www.youtube.com/watch?v=ZZJQk3cw6Y4>. Acesso em: 10 jan. 2015.

FAUSTINO, Cristiane; FURTADO, Fabiana. Mineração e Violação de Direitos: o projeto Ferro Carajás S11D, da Vale S.A. Açailândia (MA): DHesca Brasil, 2013.

GUDYNAS, Eduardo. Diez tesis urgentes sobre el nuevo extractivismo. Contextos y demandas bajo el progresismo sudamericano actual. Em: VÁRIOS AUTORES, Extractivismo, política y sociedad. Quito: CAAP (Centro Andino de Acción Popular) y CLAES (Centro Latino Americano de Ecologia Social), 2009 a, pp. 187 - 225. Disponível em: <<http://www.ambiental.net/publicaciones/GudynasNuevoExtractivismo10Tesis09x2.pdf >>. Acesso em: 08 jan. 2015.

. O novo extrativismo progressista na América do Sul. Correio da Cidadania, 2009b. Disponível em: <<http://www.correiocidadania.com. br/index.php?option=com_content \&view=article\&id=4178:amlatina27120 9\&catid=62:eduardo-gudynas\&ltemid=131 >>.Acesso em 08 jan. 2015.

Instituto Brasileiro de Mineração (IBRAM). Informações e Anállses da Economia Mineral Brasileira. Brasília: IBRAM, 2012.

Instituto Socioambiental (ISA). Consulta livre, prévia e informada na Convenção 169 da OIT. s/d. Disponível em:<< http://www.socioambiental.org/inst/esp/consulta_previa/?q=node\%2F19 >. Acesso em: 15 jan. 2015. 
KOKUBO, Christiane. Brasil: Mineração em terra indígena pode ser aprovada em 2013. O Eco, 22/02/2013. Disponível em: <<http:// www.oeco.org.br/reportagens/26919-brasil-mineracao-em-terra-indigena-pode-ser-aprovada-em-2013>>. Acesso em: 15 jan. 2015.

MAIOR, Ana Paula Caldeira Souto. Mineração. Instituto Socioambiental (ISA). s/d. Disponível em: http://pib.socioambiental.org/pt/c/terras-indigenas/ameacas,-conflitos-e-polemicas/mineracao. Acesso em: 15 jan. 2015.

MINERANDO Conflitos. Direção: Marcelo Cruz et al. Realização: Comissão Pastoral da Terra, 2014. Disponível em: $<<$ https://www.youtube.com/watch?v=nvSrlQbHLdc\#t=34>> . Acesso em: 10 jan. 2015.

Observatorio de Conflictos Mineros de América Latina (OCMAL). Mapa de conflictosmineros, proyectos y empresas mineras en América Latina. Disponível em: $<<$ http://basedatos.conflictosmineros. net/ocmal_db/»>. Acesso em: 12 jan. 2015.

ORGANIZAÇÃO INTERNACIONAL DO TRABALHO. Convenção 169. Genebra: OIT, 1989. Disponível em: <<http://portal.iphan.gov.br/ baixaFcdAnexo.do?id=3764>>. Acesso em: 15 jan. 2015

SANTOS, Milton. A Natureza do Espaço. Técnica e Tempo. Razão e Emoção. 4ª Ed. São Paulo: Editora da Universidade de São Paulo, 2006.

SCOTTO, Gabriela. Estados Nacionais, Conflitos Ambientais e Mineração na América Latina. UFF, 2011.Disponível em: <<http://www. uff.br/ivspesr/images/Artigos/ST03/ST03.2\%20Gabriela\%20Scotto. pdf $\gg$. Acesso em 08 jan. 2015.

SOUZA, Oswaldo Braga de. Deputado pede afastamento do relator do Código da Mineração. Instituto Socioambiental. Disponível em: <<http://www.socioambiental.org/pt-br/noticias-socioambientais/ deputado-pede-afastamento-do-relator-do-codigo-da-mineracao >>. Acesso em: 11 jan. 2015. 